\title{
Use of ionic liquids in extraction
}

\author{
Pavol Steltenpohl, Elena Graczová
}

Institute of Chemical and Environmental Engineering, Faculty of Chemical and Food Technology, Slovak University of Technology in Bratislava, Radlinského 9, 81237 Bratislava, Slovakia

pavol.steltenpohl@stuba.sk

\begin{abstract}
In order to separate liquid mixtures, common distillation is not always suitable, especially if relative volatility of the mixture components is close to or equals unity, thus avoiding separation based on the vapor enrichment by more volatile component. To overcome this limitation of distillation, several alternatives were suggested including pressure swing and extraction distillation. Another, principally different, separation method used for the liquid mixtures separation is liquid-liquid extraction. Separation efficiency of this method is closely related to the basic extraction solvent characteristics, capacity and selectivity. In order to minimize costs connected with extraction, new extraction solvents are developed, among which ionic liquids show high potential due to their tunable properties. Here, efficiency of traditional extraction solvent, benzene, was compared to that of tetradecyltrihexylphosphonium bis(trifluoromethylsulfonyl)imide ionic liquid in separation of ethanol from its aqueous solution. The comparison was assessed on the base of results of a counter-current extractor simulation. Further, some economic aspects of this separation procedure were discussed. Optimum consumption of extraction solvent was identified taking into account alcohol-to-water molar (mass) ratio in the final extract as optimization criterion.
\end{abstract}

Keywords: ionic liquids, azeotropic mixture separation, equipment simulation, counter-current extractor, product purity

\section{Introduction}

Environmental protection and replacement of fossil fuels by renewable sources belong to the principal issues covered by the sustainable development concept. In some countries, Brazil and USA, fossil fuels (naphtha products) are being replaced by the renewable ones (e.g. bio-ethanol) (Boddey et al., 2008).

Bio-ethanol is produced by fermentation from sugarcane or, in lower extent, from corn. Product of fermentation is aqueous solution of ethanol, from which the desired product should be separated. Due to the relatively low content of alcohol in this mixture as well as due to the large heat demand on the mixture components evaporation, distillation is not recommended for ethanol preconcentration. As an alternative for ethanol separation from water solutions liquid-liquid extraction is used. Traditionally, hydrocarbons were used as extraction solvents for this separation process. However, newly prepared solvents with better separation characteristics have potential to replace hydrocarbons in separation of ethanol and/or other lower molecular mass fermentation products.

New extraction solvents, ionic liquids (ILs), fit very well the requirements posted on extraction solvent. Their nature can be taylor-made by changing cationic or anionic part of the IL in order to suit for the selected mixture separation. The ILs major advantage over classic extraction solvents is their non-volatility that allows relatively easy and inex- pensive IL regeneration (Meindersma \& de Haan, 2008). On the other hand, massive application of ILs in separation technologies is hindered by their elevated price.

Performance of separation unit based on the liquid-liquid extraction is influenced by both the solvent capacity as well as its selectivity. Distribution coefficient (solvent capacity) conditions the extraction solvent consumption, thus influencing the equipment dimensions as well as the dimensions of separator used for the solvent regeneration from the extract. Solvent selectivity affects the extent and efficiency of separation. Consequently, this parameter is connected with the equipment dimensions (number of extractor stages) and the necessity of further separation steps used for the solvent regeneration from the final extract and the final raffinate (Meindersma et al., 2010).

Solvent regeneration, an integral part of the separation unit based on extraction, induces high investment and energy costs (Meindersma \& de Haan, 2008). In case of traditional extraction solvents, their regeneration from the final extract is done by distillation, which requires relatively high investment costs as well as high operation costs (heating and cooling media consumption). Moreover, loss of valuable solvent should be avoided by its separation from the raffinate. Then, either another separation procedure should be used or the primary separation procedure, extraction, is carried out to such extent that the content of extraction solvent in raffinate is 
negligible. However, both options require further investment and operation costs (Meindersma \& de Haan, 2008).

Use of ILs facilitates the extraction solvent regeneration due to the ILs non-volatility (Meindersma et al., 2010). Instead of distillation column, separation of the extract components could be accomplished in a simple separator, e.g. a vessel for flash distillation or stripping with an inert gas. Irrespective the extraction solvent used, after its regeneration a product stream with higher content of extracted component is obtained compared to the feed. Depending on the required product (extracted component) purity, further separation step might be required. Therefore, potential for optimization offers the selection of extraction solvent based on its separation performance.

\section{Theoretical}

Description of the liquid-liquid equilibrium was based on the isoactivity condition

$$
\gamma_{\mathrm{R} i} x_{\mathrm{R} i}=\gamma_{\mathrm{E} i} x_{\mathrm{E} i}, \quad i=1,2,3
$$

where $x_{i}$ and $\gamma_{i}$ are the $i$-th component mole fraction and activity coefficient, respectively. Subscripts E and $\mathrm{R}$ denote the extract and raffinate equilibrium phases, respectively. Calculations of the components' activity coefficients were carried out using the Non-Random Two-Liquid (NRTL) equation (Renon \& Prausnitz, 1968).

For ethanol preconcentration from aqueous solution via liquid-phase extraction (LPE) the selected traditional extraction solvent was benzene while the novel one was tetradecyltrihexylphosphonium bis(trifluoromethylsulfonyl)imide ([TDTHP] [NTf $\left.{ }_{2}\right]$ ) IL.

Simulation of the model mixture separation based on LPE was carried out assuming equilibrium model of a counter-current extraction column. Details of the extraction column model development could be found elsewhere (Steltenpohl \& Graczová, 2014).

\section{Results and discussion}

\section{Extraction solvent characteristics}

Parameters of the NRTL equation for the ternary systems considered were taken from literature and are summarized in Table 1.

Properties of extraction solvent decisive for its efficiency in LPE are distribution coefficient of the extracted component $\left(D_{2}\right)$ and solvent selectivity $\left(\beta_{21}\right)$

$$
\begin{gathered}
D_{i}=\frac{x_{\mathrm{E} i}}{x_{\mathrm{R} i}}=\frac{\gamma_{\mathrm{R} i}}{\gamma_{\mathrm{E} i}}, \quad i=1,2,3 \\
\beta_{21}=\frac{D_{2}}{D_{1}}=\frac{x_{\mathrm{E} 2} x_{\mathrm{R} 1}}{x_{\mathrm{R} 2} x_{\mathrm{E} 1}}
\end{gathered}
$$

Results of the liquid-liquid equilibrium simulation were used to compute $D_{2}$ and $\beta_{21}$ as shown in Figs. 1 and 2 , respectively.

Analyzing ethanol-water LPE, about twenty-times higher value of ethanol distribution coefficient was calculated for $[\mathrm{TDTHP}]\left[\mathrm{NTf}_{2}\right]$ in comparison with that obtained for benzene (Fig. 1). However, due to the large differences in molar mass of these two extraction solvents, the mass-based distribution coefficient of ethanol using [TDTHP] $\left[\mathrm{NTf}_{2}\right]$ is only slightly larger than $D_{2}$ computed for benzene. In the chosen concentration range the mass-based distribution coefficient values within the range of 0.05-0.15 were computed for benzene and within 0.1-0.3 for [TDTHP] $\left[\mathrm{NTf}_{2}\right]$.

In Fig. 2, extremely high values of ethanol/water selectivity for [TDTHP] $\left.\mathrm{NTf}_{2}\right]$ are shown compared to the respective values obtained for benzene.

\section{Extraction simulation}

Simulation of LPE was carried out for the input parameters given in Table 2.

Fig. 3 presents the influence of the number of equilibrium stages on the extraction solvent relative consumption in ethanol LPE.

While keeping the preset purity of the final raffinate $\left(x_{\mathrm{R} 2 N}=0.005\right)$, by increasing the number of theoreti-

Tab. 1. The NRTL model parameters for the selected ternary system at $25^{\circ} \mathrm{C}$.

\begin{tabular}{lccccc}
\hline Ternary system & Binary & $\tau_{i j}$ & $\tau_{j i}$ & $\alpha_{i j}$ & Reference \\
\hline \multirow{2}{*}{ Water (1)-ethanol (2)-benzene (3) } & $1-2$ & 1.2622 & -1.4816 & 0.2000 & \\
& $1-3$ & 9.3835 & 3.3104 & 0.2000 & Sørensen and Arlt (1980) \\
\hline & $2-3$ & 0.2943 & 0.3959 & 0.2000 & 0.3031 \\
Water (1)_ethanol (2)_[TDTHP][NTf $]$ (3) & $1-2$ & 2.2485 & -0.1851 & 0.2000 & Neves et al. (2011) \\
\hline
\end{tabular}

NRTL binary interaction, $\tau_{i j}, \tau_{j i}$, and non-randomness, $\alpha_{i j}$, parameters $(i, j=1,2,3 ; i \neq j)$. 


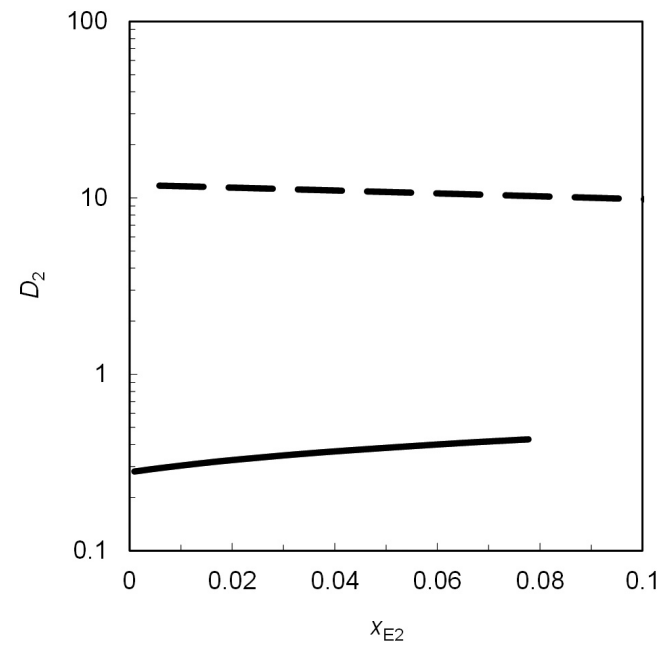

Fig. 1. Molar amount-based distribution coefficient of ethanol, $D_{2}$, vs ethanol mole fraction in extract, $x_{\mathrm{E} 2}$. Extraction solvent: benzene (solid line) and [TDTHP] $\left[\mathrm{NTf}_{2}\right]$ (dashed line).

cal stages specific consumption of extraction solvent $\left(\dot{n}_{\mathrm{S}} / \dot{n}_{\mathrm{F}}\right)$ decreases. Irrespective the calculation base (molar amount or mass) consumption of benzene, i.e. extraction solvent with lower capacity, is higher than that of $[\mathrm{TDTHP}]\left[\mathrm{NTf}_{2}\right]$. These results agree very well with comparison of the solvents extraction capacity, $D_{2}$, shown in Fig. 1.

Further simulations of LPE were conducted in order to evaluate the effect of the solvent purity on the separation of aqueous alcohol mixture. All calculations were carried out for the preset content of extracted component in the final raffinate $\left(x_{\mathrm{R} 2 N}=0.005\right)$ and the number of theoretical stages $(N=5)$. In Table 3 the increase in the extraction solvent specific consumption is presented as a function of purity of the solvents used in extraction separation.

Results in Table 3 show variation of the absolute values of the solvent amount required for extraction as a function of its purity levels given in Table 2. Further, consumption increase expressed in per cent was calculated, where $100 \%$ corresponds to pure solvent.

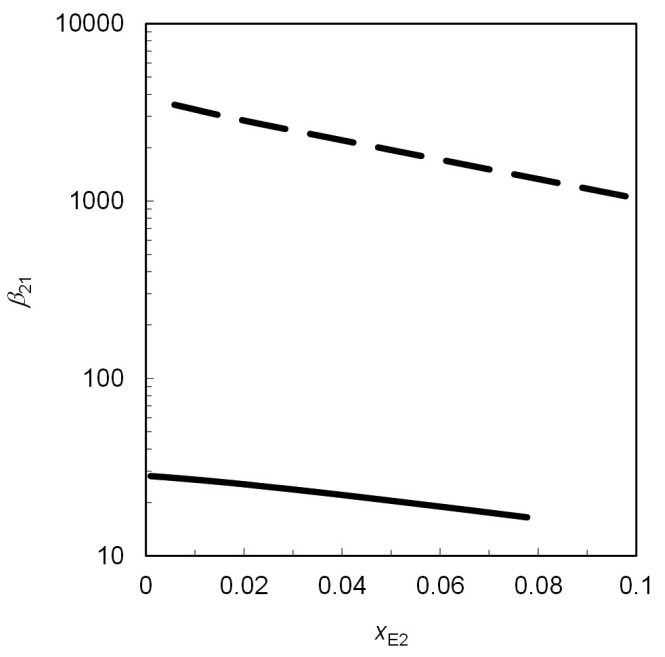

Fig. 2. Variation of the extraction solvent selectivity, $\beta_{21}$, vs ethanol mole fraction in extract, $x_{\mathrm{E} 2}$. Extraction solvent: benzene

(solid line) and [TDTHP] $\left[\mathrm{NTf}_{2}\right]$

(dashed line).

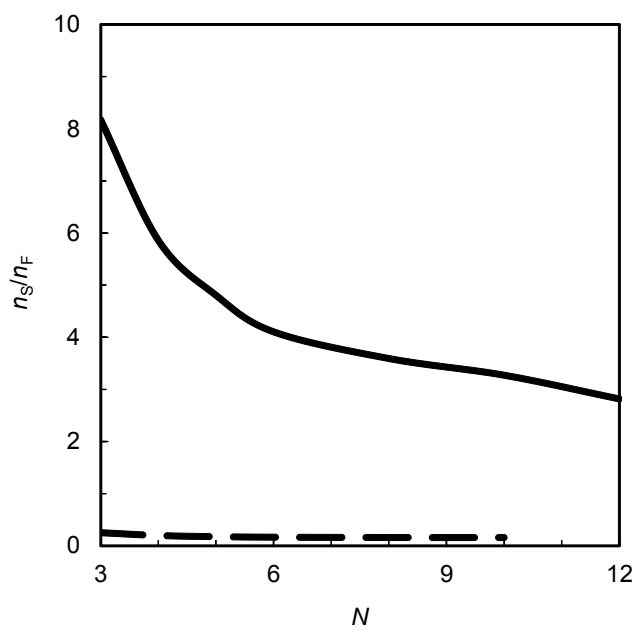

Fig. 3. Variation of the molar amount-based specific solvent consumption, $\dot{n}_{\mathrm{S}} / \dot{n}_{\mathrm{F}}$, with the number of theoretical stages, $N$. Extraction solvent: benzene (solid line) and [TDTHP] $\left.\mathrm{NTf}_{2}\right]$ (dashed line).

Tab. 2. Input data for the extractor simulations.

\begin{tabular}{cccccc}
\hline$\dot{n}_{\mathrm{F}} /\left(\mathrm{kmol} \mathrm{h}^{-1}\right)$ & $x_{\mathrm{F} 1}$ & $x_{\mathrm{F} 2}$ & $x_{\mathrm{F} 3}$ & $x_{\mathrm{R} 2 N}$ \\
\hline 10 & 0.85 & 0.15 & 0.00 & $3-12$ & 0.005 \\
\hline Solvent composition & & $x_{\mathrm{S} 1}$ & $x_{\mathrm{S} 2}$ & $x_{\mathrm{S} 3}$ \\
\hline & 1 & 0 & 0 & 0 \\
Computation set & 2 & 0.0005 & 0.0005 & 0.999 \\
& 3 & 0.001 & 0.001 & 0.998 \\
\hline
\end{tabular}

$\dot{n}$ and $N$ correspond to the molar flow and the number of equilibrium stages, respectively. Subscripts F and S denote feed and extraction solvent streams, respectively. 
Tab. 3. Variation of the extraction solvent specific consumption with its purity.

\begin{tabular}{lcccc}
\hline \multirow{2}{*}{ Impurity content/mole \% } & \multicolumn{2}{c}{$\dot{n}_{\mathrm{S}} / \dot{n}_{\mathrm{F}}$} & \multicolumn{2}{c}{$\dot{n}_{\mathrm{S}} / \dot{n}_{\mathrm{F}}$ increase $^{a} \%$} \\
\cline { 2 - 5 } & benzene & {$[\mathrm{TDTHP}][\mathrm{NTf}$} & ] \\
\hline 0.000 & 4.806 & 0.1756 & benzene & {$\left[\mathrm{TDTHP}_{[}\left[\mathrm{NTf}_{2}\right]\right.$} \\
0.001 & 5.411 & 0.1760 & 100.0 & 100.0 \\
0.002 & 6.674 & 0.1764 & 138.6 & 100.2 \\
\hline
\end{tabular}

${ }^{a}$ Increase of the extraction solvent consumption relative to its consumption while using pure solvent.

Large differences between the consumption of traditional solvent, benzene, and IL were observed.

The results of simulation of water-ethanol mixture separation show that assuming the preset final raffinate composition $\left(x_{\mathrm{R} 2 N}=0.005\right)$ and extraction column with five equilibrium stages, ethanol yield in the final extract was similar, $97.4 \%$ and $97.2 \%$ using benzene and [TDTHP] $\left[\mathrm{NTf}_{2}\right]$ as extraction solvent, respectively.

Loss of extraction solvents in the final raffinate was on the level of $10^{-4} \%$ that could be considered negligible. Finally, higher preconcentration of ethanol was achieved using IL as extraction solvent compared to benzene. This observation clearly corresponds to different solvents selectivity (Fig. 2). It was also found that up to twice as high preconcentration of ethanol could be obtained by varying [TDTHP] $\left[\mathrm{NTf}_{2}\right]$ consumption and/or number of the extraction column theoretical stages. Curiously, maximum of ethanol-to-water molar ratio in the final extract (theoretical stage 1 in the counter-current extraction column) was achieved by increasing

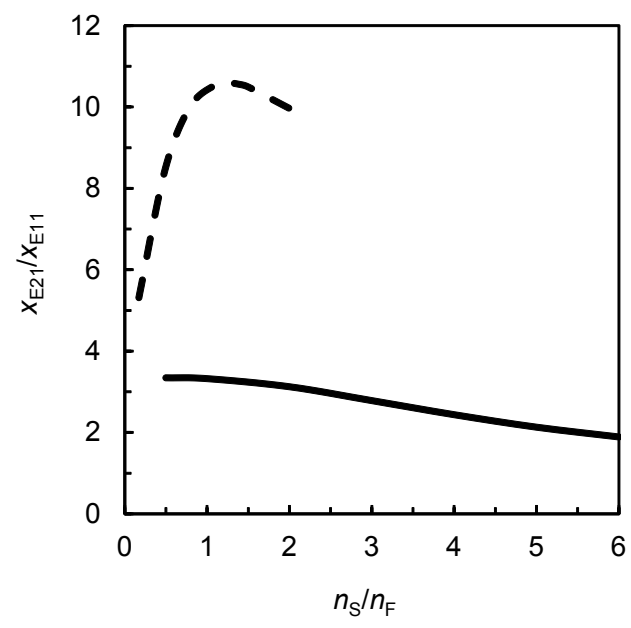

Fig. 4. Variation of the ethanol-to-water mole ratio in the final extract, $x_{\mathrm{F} 21} / x_{\mathrm{E} 11}$, as a function of benzene (solid line) and [TDTHP] $\left[\mathrm{NTf}_{2}\right]$ (dashed line) specific consumption, $\dot{n}_{\mathrm{S}} / \dot{n}_{\mathrm{F}}$.

Simulation in an extractor with five equilibrium stages using pure solvent. the $\dot{n}_{\mathrm{S}} / \dot{n}_{\mathrm{F}}$ ratio to a level of 1.25 . Further increase of the IL consumption caused a decrease of the $x_{\mathrm{E} 21} / x_{\mathrm{E} 11}$ value as shown in Fig. 4.

\section{Conclusions}

It was found that the use of ILs in LPE could improve the process efficiency. It is, however, necessary to select the ionic liquid with appropriate extraction as well as physical-chemical properties. Moreover, application of ILs allows diminishing the overall costs of the process thanks to their low consumption and good separability from the other components. On the other hand, one should bear in mind elevated price of these solvents.

Assuming ethanol preconcentration from the thermodynamics point of view, [TDTHP] $\left[\mathrm{NTf}_{2}\right]$ is much better solvent than benzene. Although ethanol yield in the final extract is similar for the two solvents considered (due to the prescribed ethanol content in final raffinate), consumption of these solvents differs considerably (Fig. 3). Considering certain levels of impurity content in the extraction solvent used, a large increase of benzene consumption was found compared to that of [TDTHP] $\left[\mathrm{NTf}_{2}\right]$ (Table 3). Necessity of the use of practically pure extraction solvent increases the costs of the spent extraction solvent regeneration.

Unexpected behavior was observed regarding the simulation of water-ethanol mixture separation in the presence of [TDTHP] $\left[\mathrm{NTf}_{2}\right]$ as extraction solvent (Fig. 4). Contrary to the common observation that preconcentration of extracted component $\left(x_{\mathrm{E} 21} / x_{\mathrm{E} 11}\right)$ decreases with increasing the amount of extraction solvent, in case of [TDTHP] $\left[\mathrm{NTf}_{2}\right]$ both purity of raffinate and ethanol preconcentration were improved up to the specific solvent consumption of $\dot{n}_{\mathrm{S}} / \dot{n}_{\mathrm{F}}=1.25$. If confirmed in technical praxis, this observation would allow further optimization of operational costs of the extraction process.

\section{Acknowledgement}

The authors acknowledge the Research and Development Assistance Agency APVV (APVV-0858-12) for financial support. 


\section{References}

Boddey RM, Soares LHB, Alves BJR, Urquiaga S (2008) In: Pimentel D (Ed) Biofuels, solar and wind as renewable energy systems: Benefits and risks (pp. 321-356). Springer, Dordrecht, DOI: 10.1007/978-14020-8654-0_13.

Meindersma GW, de Haan AB (2008) Chemical Engineering Research and Design 86: 745-752. DOI: 10.1016/j.cherd.2008.02.016.

Meindersma GW, Hansmeier AR, de Haan AB (2010) Industrial \& Engineering Chemistry Research 49: 7530-7540. DOI: 10.1021/ie100703p.
Neves CMSS, Granjo JFO, Freire MG, Robertson A, Oliveira NMC, Coutinho JAP (2011) Green Chemistry 13: 1517-1526. DOI: 10.1039/c1 gc15079k.

Renon H, Prausnitz JM (1968) AIChE Journal 14: 135-144. DOI: 10.1002/aic.690140124.

Sørensen JM, Arlt W (1980) Liquid-liquid equilibrium data collection: Ternary systems (Vol. V, Part 2, pp. 352). DECHEMA, Frankfurt/Main.

Steltenpohl P, Graczová E (2014) Chemical Engineering Transactions 39: 187-192. DOI: 10.3303/ cet 1439032 . 